\title{
Medical Image of the Week: Asbestos Related Pleural Disease
}

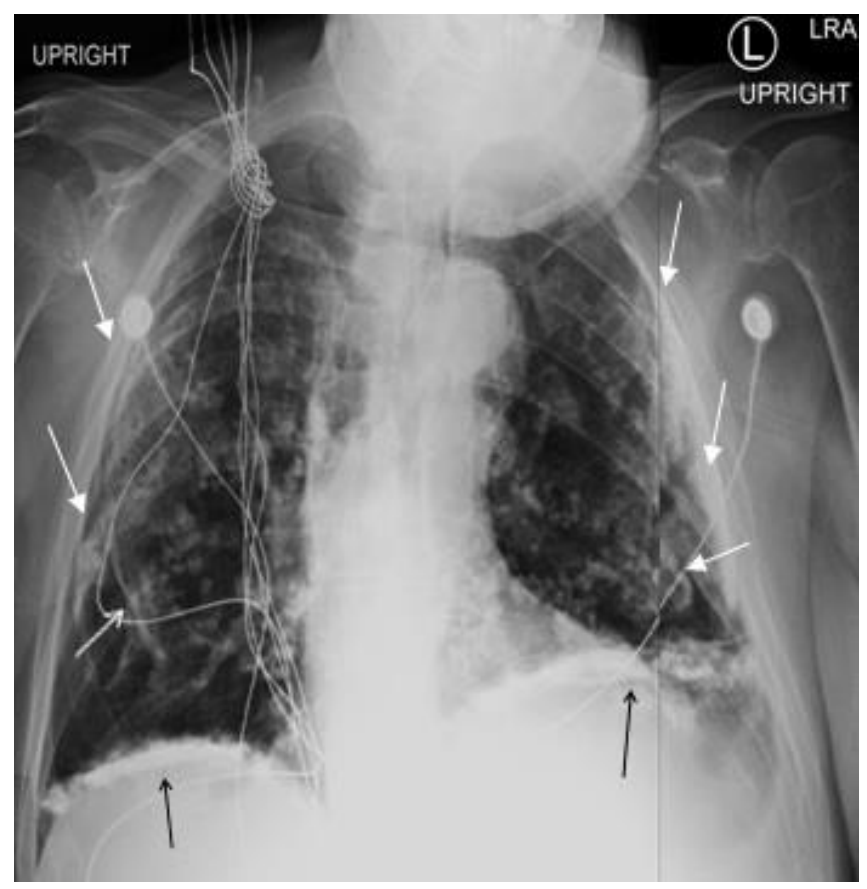

Figure 1. Chest radiograph demonstrates bilateral coarse calcification, most elongated and vertically oriented in nature (white arrows). Also note coarse calcification outlining the hemidiaphragms (dark arrows). Editor's note: the patient's only chest x-ray was two different AP views which are merged above.

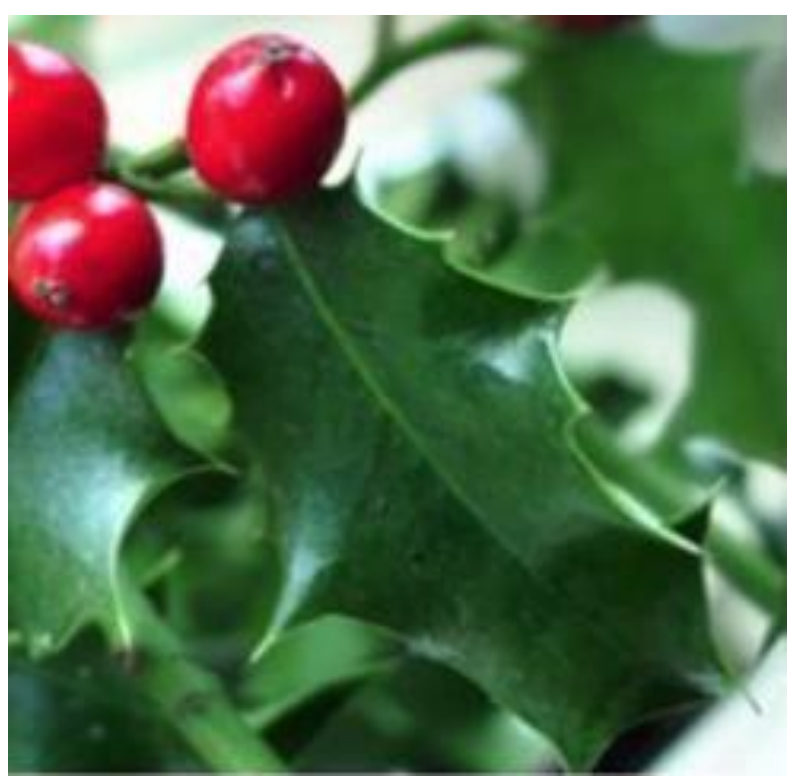

Figure 2. Holly leaf. Its shape is similar to the irregular thickened nodular edges of pleural plaques on chest radiograph, referred to as "the holly leaf sign". 


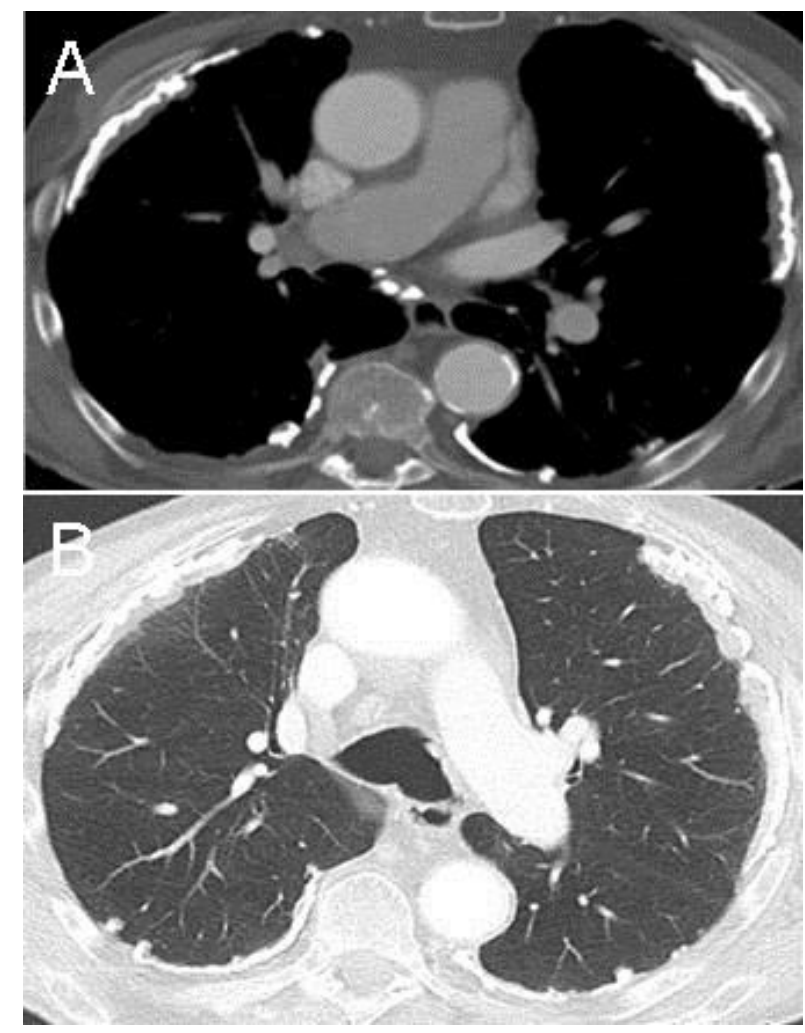

Figure 3. Thoracic CT shown in soft tissue (A: top) and lung (B: bottom) windows clearly localizes the calcifications to the parietal pleura.

Pleural plaques are strongly associated with inhalational exposure to asbestos (1). The lesions may take up to thirty years to develop. Plaques are typically bilateral, involve the parietal pleura, commonly along the sixth through ninth ribs and are usually absent at the lung apices and costophrenic sulci (Figures 1 and 3). On chest radiograph, the "holly leaf sign" refers to the shape of the calcifications with thickened rolled and nodular edges (Figure 2). The plaques per se are benign in nature. However, they can potentially impair lung function, resulting in restriction. They are also markers of the individual's greater risk of developing a lung cancer or mesothelioma.

Wesley Hunter MS IV 1 , Veronica Arteaga MD², and Diana Palacio MD² ${ }^{1}$ College of Medicine and ${ }^{2}$ Department of Medical Imaging University of Arizona Tucson, AZ USA

\section{Reference}

1. Norbet C, Joseph A, Rossi SS, Bhalla S, Gutierrez FR. Asbestos-related lung disease: a pictorial review. Curr Probl Diagn Radiol. 2015 Jul-Aug;44(4):371-82. [CrossRef] [PubMed] 